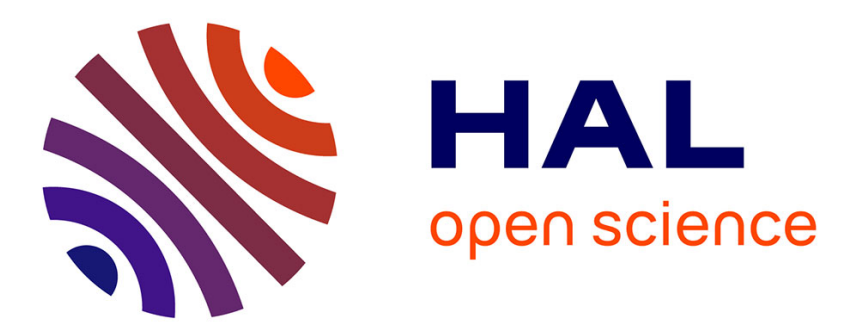

\title{
Filtration performance and pore size distribution of hypochlorite aged PES/PVP ultrafiltration membranes
}

Bastien Pellegrin, Fernanda Mezzari, Yamina Hanafi, Anthony Szymczyk, Jean-Christophe Remigy, Christel Causserand

\section{- To cite this version:}

Bastien Pellegrin, Fernanda Mezzari, Yamina Hanafi, Anthony Szymczyk, Jean-Christophe Remigy, et al. Filtration performance and pore size distribution of hypochlorite aged PES/PVP ultrafiltration membranes. Journal of Membrane Science, 2015, 474, pp.175-186. 10.1016/j.memsci.2014.09.028 . hal-01115957

\section{HAL Id: hal-01115957 \\ https://hal-univ-rennes1.archives-ouvertes.fr/hal-01115957}

Submitted on 2 Jul 2015

HAL is a multi-disciplinary open access archive for the deposit and dissemination of scientific research documents, whether they are published or not. The documents may come from teaching and research institutions in France or abroad, or from public or private research centers.
L'archive ouverte pluridisciplinaire HAL, est destinée au dépôt et à la diffusion de documents scientifiques de niveau recherche, publiés ou non, émanant des établissements d'enseignement et de recherche français ou étrangers, des laboratoires publics ou privés. 


\title{
Filtration performance and pore size distribution of hypochlorite aged PES/PVP ultrafiltration membranes
}

\author{
Bastien Pellegrin $^{\mathrm{a}, \mathrm{b}}$, Fernanda Mezzari ${ }^{\mathrm{a}, \mathrm{b}}$, Yamina Hanafi ${ }^{\mathrm{c}}$, Anthony Szymczyk ${ }^{\mathrm{c}}$, \\ Jean-Christophe Remigy ${ }^{\mathrm{a}, \mathrm{b}}$, Christel Causserand ${ }^{\mathrm{a}, \mathrm{b},{ }^{*}}$
}

${ }^{\text {a }}$ Université de Toulouse, INPT, UPS, Laboratoire de Génie Chimique, 118 route de Narbonne, F-31062 Toulouse cedex 09, France

${ }^{\mathrm{b}}$ CNRS, UMR 5503, Laboratoire de Génie Chimique, F-31062 Toulouse, France

'Université de Rennes 1, Institut des Sciences Chimiques de Rennes, UMR CNRS 6226, 263

Avenue du Général Leclerc, 35042 Rennes Cedex, France

\begin{abstract}
The objective of the present work is to correlate the evolution of membrane characteristics due to contact with hypochlorite used as cleaning agent to its selectivity towards model solutes. Accelerated ageing experiments were performed by soaking the membrane at ambient temperature in hypochlorite solutions. The total free chlorine concentration of these solutions was fixed at $350 \mathrm{ppm}$ and the $\mathrm{pH}$ at 8 . The model solute selected was T500 Dextran. The experimental results demonstrated that hypochlorite induced membrane degradation, on one hand modified the solutes-membrane interactions increasing irreversible fouling and, on the other hand, lowered the selectivity. These results have been correlated to the modification of the pore size distribution following a protocol in which fouling did not affect membrane characterization. The most probable scenario of distribution evolution over degradation process was an increase of the pore radius of the initial population, accompanied by a decrease in their number, coupled with the appearance of defects, whose radius increased with the progress of the degradation.
\end{abstract}

\section{Keywords}

Ultrafiltration membrane; Permeability; Selectivity; Pore size distribution; ageing

*Corresponding author: caussera@ chimie.ups-tlse.fr

(Phone: +33 5615586 90; Fax: +33 5615561 39) 


\section{Introduction}

To get rid of reversible and irreversible membrane fouling and ensure proper operation, drinking water production by ultrafiltration (UF) involves back-washing and chemical cleaning. A wide range of cleaning agents is used onsite: hydrochloric acid, sodium hydroxide and oxidants such as hydrogen peroxide $\left(\mathrm{H}_{2} \mathrm{O}_{2}\right)$ and sodium hypochlorite $(\mathrm{NaClO})$. The latter one remains so far the most common choice due to its availability, reasonable price and antibacterial/oxidizing properties [1]. Depending on the characteristics of the water treated, operators may use $\mathrm{NaClO}$ solutions with a total free chlorine (TFC) concentration ranging from 2 to $20 \mathrm{ppm}$ for a maximum duration of 5 min for back-washing and with a [TFC] from 20 to $400 \mathrm{ppm}$ for a maximum duration of $2 \mathrm{~h}$ for chemical cleaning. Frequencies may reach, for back-washing and chemical cleaning respectively, 1 per $6 \mathrm{~h}$ and 1 per month of membrane operation. As major water treatment facilities appear to be subjected to membrane failure and integrity loss on a quite regular basis [2], the impact of industrial washing on membrane properties has recently become a key issue.

Ultrafiltration processes commonly use polyacrylonitrile (PAN), polyvinyl chloridepolyacrylonitrile (PVC/PAN) copolymers, polysulfone (PSf), polyethersulfone (PES), polyvinylidene fluoride (PVDF), aromatic polyamide (PA) or cellulose acetate (CA) as membrane materials [3]. Among them, PES exhibiting good chemical resistance, mechanical properties and thermal stability appears as a first-choice polymeric material for UF membrane formulation. However this polymer being quite hydrophobic, the addition of a more hydrophilic polymer such as poly(N-vinylpyrrolidone) (PVP) in the dope has then become a standard method to increase water permeability and lower the membrane propensity to fouling.

The studies concerning the role played by sodium hypochlorite on PES Ultrafiltration membranes [4-13] mainly focus on changes in the macromolecular chemical composition, hydrophilic character, permeability and mechanical properties. However, the impact of $\mathrm{NaClO}$ on membrane selectivity by means of tracer's retention measurements (and selectivity curve determination) has not been thoroughly investigated and understood. The few available publications concerning the effects of the cleaning agent $\mathrm{NaClO}$ on retention properties of PES UF membranes $[4,5,9,12,13]$ only mention the observed retention without taking into account the evolution of permeability, consequently ignoring the impact of concentration polarization and possible fouling on the final retention results. In addition, in most cases, proteins are used as tracers even though they are known to have greater interaction with the membrane material compared to polymeric ones.

In 1995, Wienk et al. [4] first reported an increase of pure water flux through PES/PVP membranes attributed to PVP degradation and leaching during membrane immersion in a $4000 \mathrm{ppm} \mathrm{NaClO}$ solution under stirring. Moreover these authors showed that, despite an increase in water permeability, $\mathrm{NaClO}$ treated PES/PVP membrane exhibited high (90\%) and unchanged retention for bovine serum albumin, suggesting that the overall pore structure experienced minimal changes. Later on, Qin et al. [5] confirmed the permeability increase observed by Wienk et al. and showed an alteration of retention properties of PES/PVP membranes soaked in $\mathrm{NaClO}$ solutions. Retention of PVP $24 \mathrm{kDa}$ by the membrane decreased after $\mathrm{NaClO}$ treatment although the retention of BSA $66 \mathrm{kDa}$ was unchanged. The authors suggested that the small pores involved in the retention of PVP $24 \mathrm{kDa}$ were greater after $\mathrm{NaClO}$ contact while the large pores involved in BSA retention were similar. They then concluded that the membrane pore size distribution became narrower after the hypochlorite treatment, without providing any quantitative analysis of these changes. 
More recently, various authors reported an alteration of the mechanical properties of PES/PVP systems attributed by the authors not to PVP but to PES chain scissions [7, 9-13]. Arkhangelsky et al. [9] and Levitski et al. [13] went further in the study of the impact of hypochlorite cleaning on membrane selectivity. They measured observed membrane retention of BSA, viruses, Dextrans and polyethylene glycols (PEG) of different molecular weights. They first showed that a $\mathrm{NaClO}$ treated PES membrane exhibited an increased tendency to fouling with rising hypochlorite concentration. In term of selectivity evolution, they obtained contradictory results after $\mathrm{NaClO}$ treatment: an increase in BSA, Dextrans and PEG molecules retention and a significant reduction in viral retention. When the transfer of viruses was linked to enlargement of membrane pores size, the results with protein and soluble polymers were ascribed to an important adsorption on the modified membrane surface making it impossible the determination of the pore size distribution like this has been done by the authors on virgin membrane [9]. The authors concluded that pore size enlargement due to PES chain scission is not detrimental to membrane retention (especially towards proteins) which is governed by a higher membrane propensity to adsorption. Even if Yadav and Morison [12] proposed the same degradation mechanism leading to chain scission of the PES polymer, their results were contradictory to the ones of Levitski et al. [13] in terms of consequences on membrane selectivity. Yadav and Morison [12] agreed that PES scission alters proteins/PES interaction leading to a higher adsorption and a lower flux, but for them localized chain scission leads to "pitting" of PES exposing larger pores and as a consequence increasing protein transfer.

Although these works clearly demonstrate that hypochlorite sodium treatment modifies membrane performances, there are still contradictory conclusions on pore size distribution evolution and its consequence on membrane selectivity. In the domain of hemodialysis using PSf hollow fiber membranes, the study conducted by Wolff and Zydney [14] has to be mentioned. These authors focalized their work on changes in membrane pore size due to bleach exposure of PSf/PVP hemodialysis membranes and provided the first quantitative analysis of the effect of bleach on transport properties of this type of hollow fiber. Similar study on ultrafiltration PES membrane is not yet available.

The present work is mainly focused on the alterations of filtration properties, i.e. permeability and selectivity, caused by the contact between PES/PVP UF membranes and sodium hypochlorite. In this context, we aim to obtain retention as an intrinsic characteristic of pristine and aged membranes while tracking the changes in permeability.

In a former work $[15,16]$ the role of sodium hypochlorite exposure conditions, especially the solution $\mathrm{pH}$, on membrane characteristics has been investigated through a series of accelerated ageing experiments. The membrane was a commercially available PES/PVP hollow fiber widely used for drinking water production, the molecular weight cut-off provided by the manufacturer being $150 \mathrm{kDa}$. Monitoring the hydraulic permeability, mechanical properties and chemical structure evolutions showed, on multiple scales, strong indications of the membrane chemical degradation (increase in water permeability, decrease in elongation at break). It was confirmed that hypochlorite exposure induces PVP radical degradation (involving PVP chain scissions) and dislodgement from the PES matrix, leading to an increase of the pure water permeability and to an embrittlement of the membrane. Advanced chemical analysis brought direct evidence of PES oxidation, occurring only within the first 40 $\mu \mathrm{m}$ of the membrane thickness, where PVP is present. It was then shown that the presence of PVP and / or PVP degradation products is a required condition for PES oxidation to occur. Finally it was shown that the $\mathrm{pH}$ range $7-8$, corresponding to the maximum radical $\mathrm{HO}^{\circ}$ concentration in solution, corresponds to the most severe modification in the membrane mechanical properties and permeability. 
The objective of the present work was to correlate the evolution of membrane characteristics to its selectivity for model solutes. Accelerated ageing experiments were performed (as in previous works $[15,16])$ by soaking the membrane at ambient temperature in hypochlorite solutions at a total free chlorine concentration of $350 \mathrm{ppm}$ and $\mathrm{pH} 8$. The model solute selected was a polydisperse Dextran, which is classically used to determine membrane molecular weight cut-off. Conditions minimizing fouling during membrane characterization were searched in order to reach intrinsic membrane selectivity. The experimental results obtained with Dextrans have been used to propose scenario of pore size distribution modification. The most probable scenario of distribution evolution over degradation process was then investigated.

\section{Theory}

The permeability and the selectivity of a membrane both depend of the pore size distribution in the selective skin. Charge effects can also affect selectivity but this phenomenon will be considered negligible in this paper as tracers used are neutral.

In the case of steric retention of a spherical solute, it is possible to estimate the retention rate by the membrane $R_{m}$ using the Ferry law, through considerations based on the solvent and the solute flow in a cylindrical pore the radius of which is $r_{p}$ :

$$
R_{m}=\left(1-\left(1-\frac{R_{h y d}}{r_{p}}\right)^{2}\right)^{2}
$$

In this equation $R_{h y d}$ represents the hydrodynamic radius of the solute in solution. This radius can be linked to the hydrodynamic volume of a polymer random coil in solution using the following equation [17]:

$$
R_{h y d}=\left(\frac{3 \eta M_{W}}{4 \xi N_{A}}\right)^{\frac{1}{3}}
$$

with:

- $\quad \eta \quad$ the intrinsic viscosity of the solution $\left(\mathrm{m}^{3} \mathrm{~g}^{-1}\right)$

- $\quad \mathrm{M}_{\mathrm{W}}$ the molar mass of the polymer $\left(\mathrm{g} \mathrm{mol}^{-1}\right)$

- $\mathrm{N}_{\mathrm{A}}$ the Avogadro number $\left(6.022 .10^{23} \mathrm{~mol}^{-1}\right)$

- $\xi$ the factor shape equal to the ratio of the radius of the equivalent sphere and the radius of gyration of the polymer molecule (taken equal to 1).

In the case of Dextrans, an empirical relation can be used to calculate the intrinsic viscosity knowing the Dextran molecule molar mass if this belongs to the range from $40000 \mathrm{~g} \mathrm{~mol}^{-1}$ to $2000000 \mathrm{~g} \mathrm{~mol}^{-1}[18]:$

$$
\eta=4.9 * 10^{-8} \mathrm{M}_{\mathrm{W}}^{0.672}
$$

We can also estimate the flow rate $Q$ at the temperature $20^{\circ} \mathrm{C}$ through a single cylindrical, straight pore of radius $r_{p}$ and length $l$ according the Hagen-Poiseuille law [19]: 


$$
Q=\frac{\pi T M P r_{p}^{4}}{8 \mu_{20} l}
$$

with:

- TMP the transmembrane pressure $(\mathrm{Pa})$

- $\mu_{20} \quad$ the dynamic viscosity of the fluid at a temperature of $20^{\circ} \mathrm{C}(\mathrm{Pa} \mathrm{s})$.

In the literature, several authors have demonstrated that a log-normal law generally provides a good representation of the pore size distribution for ultrafiltration membranes [20, 21]. In this work, we choose a discrete log-normal law that defines the probability to find a pore radius in a class of radius [22]. The pore radius follows a geometric progression: $\mathrm{r}_{\mathrm{i}}=\beta r_{i+1}$, with $\beta=$ 1.025. This leads to the number of pores of radius $r_{i}$ per membrane unit area:

$$
n\left(r_{i}\right)=\frac{N_{\text {pore }}}{\sqrt{2 \pi} \sigma r_{i}} \exp \left(-\frac{1}{2}\left(\frac{\ln \left(r_{i}\right)-\ln \left(r_{\text {pore }}\right)}{\sigma}\right)^{2}\right) \delta r_{i}
$$

with:

- $N_{\text {pore }}$ the total number of pores per unit area

- $r_{\text {pore }}$ the radius of the pores with the largest population (maximum of the lognormal function)

- $\sigma \quad$ the geometric standard deviation of the log-normal function

- $\delta r_{i} \quad$ the actual gap between two consecutive classes of pores $\left(\delta r_{i}=r_{i+1}-r_{i}\right)$

The combination of Eqs (4) and (5) leads to the following expression for the membrane permeability (at $\left.20^{\circ} \mathrm{C}\right)$ :

$$
\frac{L_{P}}{\mu_{20}}=\frac{J}{T M P}=\frac{1}{T M P} \sum_{i} J\left(r_{i}\right)=\frac{1}{T M P} \sum_{i} Q\left(r_{i}\right) n\left(r_{i}\right)=\sum_{i} \frac{\pi}{8 \mu_{20} l} n\left(r_{i}\right) r_{i}^{4}
$$

Finally, the membrane retention can be obtained by the sum of the retentions calculated for each class of pore size (Eq 1) balanced by their respective flux density $J\left(r_{i}\right)$, all being normalized by the total flux density $J$ :

$$
R_{m}=\frac{1}{J} \sum_{i} J\left(r_{i}\right)\left(1-\left(1-\frac{R_{h y d}}{r_{i}}\right)^{2}\right)^{2}=\frac{1}{J} \sum_{i} \frac{\pi n\left(r_{i}\right) r_{i}^{4}\left(1-\left(1-\frac{R_{h y d}}{r_{i}}\right)^{2}\right)^{2}}{8 \mu_{20} l}
$$

\section{Experimental}

\subsection{Membranes}

The membranes used in this study are commercially available hollow fibers extracted from a new UF module (HYDRACAP 60, LD HYDRANAUTICS Membrane), widely used for drinking water production. Those hollow fibers present an asymmetric geometry with an inner selective layer, an internal diameter of $0.8 \mathrm{~mm}$ and an external diameter of $1.3 \mathrm{~mm}$ (Fig. 1). 
Manufacturer datasheet specifies a molecular weight cut-off (MWCO) of $150 \mathrm{kDa}$, a maximum operating trans-membrane pressure (TMP) of 1.4 bar and a maximum chlorine exposure of 200,000 ppm h ( $200 \mathrm{~g} \mathrm{~h} \mathrm{~L}^{-1}$ ) ([TFC] of the $\mathrm{NaClO}$ soaking solution multiplied by the sample- $\mathrm{NaClO}$ exposure time). The membrane material is claimed to be a "hydrophilized" PES. As previously shown [16] the additive used for the membrane surface hydrophilization has been identified by ATR-IR to be PVP.

Figure 1: Cross-section SEM image of a cryo-fractured pristine membrane

After extraction from the module, the hollow fibers were stored in a $1 \mathrm{~g} \mathrm{~L}^{-1}$ sodium metabisulfite $\left(\mathrm{Na}_{2} \mathrm{O}_{5} \mathrm{~S}_{2}-\right.$ Techn cai grace $85 \%$, Sigma-Aldrich, USA) solution at $5{ }^{\circ} \mathrm{C}$ to avoid bacterial proliferation. Prior to usin s, membrane samples were soaked in a large volume of ultra-pure water for at least $1 \mathrm{r}$ to remc ve sodium metabisulfite.

\subsection{Solutions and analytical method}

All aqueous solutions were prepared using deionized ultrapure water $(\rho=18.2 \mathrm{M} \Omega \mathrm{cm}$ ) generated by a PURELAB Maxima system (ELGA LabWater's, UK).

The selected tracer is T 500 Dextran (Pharmacosmos), a polydisperse polysaccharide covering a broad molar mass range from $25 \mathrm{~kg} \mathrm{~mol}^{-1}$ to more than $4000 \mathrm{~kg} \mathrm{~mol}^{-1}$. The feed Dextran solution was prepared at the concentration of $1 \mathrm{~g} \mathrm{~L}^{-1}$. Retentate and permeate samples collected during filtration tests were analyzed by gel permeation chromatography using a column OHpak SB-805 HQ (Shodex) coupled with a refractive index detector. To prevent bacterial growth, as these samples have been stored in the fridge before analysis, sodium azide (Aldrich) was added at a concentration of $0.1 \mathrm{~g} \mathrm{~L}^{-1}$ in the feed Dextran solution.

Hypochlorite solutions used for the ageing experiments were obtained by dilution of a commercial $\mathrm{NaClO}$ reagent ( $\mathrm{NaClO} 9.8 \mathrm{wt} \%$ - La Croix, FR). Concentrated sulfuric acid $\left(\mathrm{H}_{2} \mathrm{SO}_{4}\right.$ - Analytical grade $95 \%$, VWR PROLABO, FR) was added to the hypochlorite ageing solutions to adjust the $\mathrm{pH}$ at a value of 8 .

\subsection{Ageing protocol}

Ageing experiments were performed by soaking the membranes at ambient temperature (20 \pm $2^{\circ} \mathrm{C}$ ) in an hypochlorite solution at a total free chlorine concentration ([TFC]) of $350 \mathrm{ppm}(\mathrm{mg}$ $\mathrm{L}^{-1}$ ). Exposure times investigated in the present paper were 2, 4 and $24 \mathrm{~h}$ corresponding to hypochlorite doses of 700, 1400 and $8400 \mathrm{ppm}$ h respectively.

[TFC] was monitored using DPD method (method which employs N,N-Dimethyl-pphenylenediamine-EPA-approved method $4500 \mathrm{CI}$ G) previously described [16]. Since [TFC] and $\mathrm{pH}$ were found to be decreasing with time, constant $[\mathrm{TFC}]( \pm 30 \mathrm{ppm})$ and $\mathrm{pH}( \pm 0.2)$ were maintained by adjustment of the soaking solutions as often as necessary for the $24 \mathrm{~h}$ exposure time experiment. 
After each ageing experiment, samples were soaked in a large volume of ultra-pure water for $2 \mathrm{~h}$ and stored in a $1 \mathrm{~g} \mathrm{~L}^{-1} \mathrm{Na}_{2} \mathrm{O}_{5} \mathrm{~S}_{2}$ solution at $5{ }^{\circ} \mathrm{C}$ for further analysis.

\subsection{Membrane Characterization}

\subsubsection{Filtration performance}

Membrane water permeability and tracers retention were determined using a cross flow filtration set up as schematically described in figure 2. The solutions (pure water or Dextran solution) were introduced in a $20 \mathrm{~L}$ glass tank in which the temperature was maintained at 20 $\pm 2{ }^{\circ} \mathrm{C}$. The solution was forced to permeate from the inside to the outside of a module comprising 15 fibers of $220 \pm 5 \mathrm{~mm}$ length. The total membrane surface area was then $8.3 \pm 0.210^{-3} \mathrm{~m}^{2}$. Before use, each module was compacted with ultra-pure water at maximal pressure of 1.4 bar until permeation flux stabilization $(40-60 \mathrm{~min}$ ). In all experiments, the hydrodynamic conditions correspond to laminar flow with nevertheless quite a high Reynolds number $R_{e}$ around 1800 in order to minimize concentration polarization during Dextran filtration.

Figure 2: Experimental set-up

\section{Permeability measurements}

The pure water flux $J_{T}$ was measured with pristine and hypochlorite aged membrane at various transmembrane pressures ranging from 0.5 to 1.4 bar. The flux density $J_{T}$ was corrected back to $J_{20}$ using the empirical Arrhenius law, whenever necessary:

With:

$$
J_{20}=J_{T} \frac{\mu_{T}}{\mu_{20}}=J_{T} \exp \left(\frac{E_{0}}{R T}-\frac{E_{0}}{293 R}\right)
$$

- $J_{T} \quad$ permeate flux density at temperature $T\left(\mathrm{~L} \mathrm{~h}^{-1} \mathrm{~m}^{-2}\right.$ or $\left.\mathrm{m}^{3} \mathrm{~s}^{-1} \mathrm{~m}^{-2}\right)$

- $J_{20}$ permeate flux density at temperature $20^{\circ} \mathrm{C}\left(\mathrm{L} \mathrm{h}^{-1} \mathrm{~m}^{-2}\right.$ or m $\left.\mathrm{m}^{3} \mathrm{~s}^{-1} \mathrm{~m}^{-2}\right)$

- $\mu_{T} \quad$ dynamic viscosity of the fluid at temperature $T(\mathrm{~Pa} \mathrm{~s})$

- $E_{0} \quad$ activation energy of the fluid (15 $675 \mathrm{~J} \mathrm{~mol}^{-1}$ for water)

- $\quad R \quad$ universal gas constant $\left(8.314 \mathrm{~J} \mathrm{~mol}^{-1} \mathrm{~K}^{-1}\right)$

Using the Darcy law, the pure water permeability $\frac{L_{P}}{\mu_{20}}\left(\right.$ in $\mathrm{h} \mathrm{h}^{-1} \mathrm{~m}^{-2}$ bar $\left.^{-1}\right)$ was then taken as the slope of the linear regression between TMP and $J_{20}$ values.

The accuracy on the value of $\frac{L_{P}}{\mu_{20}}$ was estimated around $8 \%$.

\section{Solutes retention}

For Dextran filtration tests, the desired TMP was adjusted in the range 0.4-0.6 bar $(0.4,0.5$, 0.55 and 0.6 bar). Retentate and permeate were recycled in the feed tank to maintain a constant volume (and tracer concentration). For each TMP, once the flux reached stabilization, permeate and retentate samples were collected for subsequent chromatography 
analysis. From a comparison between the elution curves for the retentate and the permeate, we calculated for each Dextran fraction $\alpha$ the observed retention coefficient $R_{o b o b s}$ defined by the relationship:

Where

$$
R_{\alpha, o b s}=\left(1-\frac{C_{\alpha, p}}{C_{\alpha, r}}\right) \times 100
$$

- $\mathrm{C}_{\alpha, \mathrm{p}}$ the concentration of Dextran fraction $\alpha$ in the permeate $\left(\mathrm{g} \mathrm{L}^{-1}\right)$

- $\mathrm{C}_{\alpha, \mathrm{r}} \quad$ the concentration of Dextran fraction $\alpha$ in the retentate $\left(\mathrm{g} \mathrm{L}^{-1}\right)$

To eliminate the contribution of the concentration polarization on retention, for each Dextran fraction, the term $\ln \left(1-R_{\alpha, o b s}\right) / R_{\infty o b s s}$ was plotted versus flux $J_{20}$ and extrapolated to zero flux in order to reach the membrane retention $R_{\alpha, m}$ according to the film relationship [23]:

$$
\ln \left(\frac{1-R_{\alpha, o b s}}{R_{\alpha, o b s}}\right)=\ln \left(\frac{1-R_{\alpha, m}}{R_{\alpha, m}}\right)+\frac{J_{20}}{k_{B L}}
$$

With $k_{B L}$ the mass transfer coefficient in the boundary layer $\left(\mathrm{m} \mathrm{s}^{-1}\right)$.

Each intrinsic rejection curve $\left(R_{m}\right.$ versus Dextran molar mass $M_{D e x t}$ or hydrodynamic radius $R_{h v d}$ ) has been determined using a micro-module comprising 15 fibers of $220+/-5 \mathrm{~mm}$ length. Intrinsic rejection curves reflect then the mean response of 15 individual fibers. Regarding the reproducibility of the results, for pristine and $8400 \mathrm{ppm}$.h aged membranes ( $24 \mathrm{~h}$ soaking), 2 distinct modules have been tested and exhibited very consistent results

\subsubsection{Bubble point measurement}

The protocol consists of pressurizing, using synthetic compressed air, the lumens of submerged membranes in high purity water at $20^{\circ} \mathrm{C}$, up to the observation of the formation of the first bubble of gas on the outer surface of the membrane. A minimum of 10 different measurements was conducted. The pressures of appearance of the first bubble $\left(\mathrm{P}_{\mathrm{b}}\right)$ reported in this paper correspond to averaged values calculated from these 10 tests. The accuracy of the measured pressures was estimated to $2 \%$ for pristine membrane and $11 \%$ for aged samples.

From these pressures, it is possible to calculate the radius of the largest pore $r_{\max }$ from the Young-Laplace equation describing the capillary pressure in a tube:

$$
r_{\max }=\frac{2 \gamma \cos (\theta)}{P_{b}}
$$

With:

- $\gamma \quad$ Surface tension of water at $20{ }^{\circ} \mathrm{C}\left(0.0728 \mathrm{~N} \mathrm{~m}^{-1}\right)$

- $\theta$ Contact angle between a water drop and the membrane surface (rad).

\subsubsection{Hydrophilic / hydrophobic character}

The captive bubble method was used to evaluate the hydrophilic character of the internal surface of membrane samples (skin surface) before and after ageing. The samples were first 
cut and glued on a microscope slide then immersed in the measuring cell filled with water. Air bubbles, with a fixed diameter, were formed using a micro-syringe and deposited on the skin surface of the membrane. The contact angle $\theta$ was measured on the images recorded using a goniometer DGD Fast/60, GBX. For each condition analyzed, a minimum of 4 measurements were performed and averaged. The accuracy of the measured contact angle was estimated to $7 \%$.

This method is more appropriate than the sessile drop method in the case of porous material; in these conditions, the membrane surface is in a wet state as in the case of water filtration: hydrophilic polymer chains at the membrane surface are then in contact of water. The measurement is then more realistic than the measurement performed on a dried membrane.

\subsubsection{Zeta potential}

Tangential streaming current measurements were performed through the lumen of both pristine and aged hollow fibers by means of a SurPASS electrokinetic analyzer (Anton Paar $\mathrm{GmbH}$, Austria). Each measurement was carried out with a single fiber $(5 \mathrm{~cm}$ in length) inserted in a sample holder designed for hollow fiber membranes.

Prior to measurements a millimolar $\mathrm{KCl}$ solution whose $\mathrm{pH}$ was adjusted at 5.50+/- 0.05 was circulated along the membrane for ca. $2 \mathrm{~h}$ to allow equilibration of the system. The solution flow was created by a pair of syringe pumps, which enabled to reverse the flow direction periodically. After equilibration, the streaming current was measured by means of a pair of large-area $\mathrm{Ag} / \mathrm{AgCl}$ electrodes $\left(10 \mathrm{~cm}^{2}\right)$ and recorded for increasing pressure differences up to 300 mbar. Using electrodes with a large surface area and alternating the direction of solution flow limits the electrode polarization during streaming current measurements.

As shown in Figure 1, the membrane structure is asymmetric with the central part of the fiber having pores of several micrometers in diameter. Consequently, a non negligible part of the experimental streaming current is likely to flow through the porous structure of the fiber, and not only through the lumen of the fiber [24]. In other words, both the pore surface and the lumen surface contribute to the value of streaming current experimentally accessible. Although it is possible to separate the two contributions for flat membrane samples (see [25] and [26]) and thus determining the zeta potential of the top surface and that of the pore surface, this cannot be achieved with hollow fibers because of the inability of varying the cross section of the streaming channel [24]. Nonetheless, measuring the overall streaming current flowing through the membrane remains an efficient way to give evidence of surface modifications of different membrane samples.

The tangential streaming current was measured with pristine and on aged membranes soaked 2 and $24 \mathrm{~h}$ in $\mathrm{NaClO}$ (350 ppm, pH 8). All experiments were performed at room temperature $\left(20 \pm 2{ }^{\circ} \mathrm{C}\right)$. Each measurement was repeated three times.

\subsubsection{Membrane morphology}

SEM images of pristine and aged membranes were recorded using a HITACHI Tabletop Microscope TM-1000 or a JEOL JSM 6700F Field emission gun-SEM, depending on the expected magnification. Prior to analysis, the membrane samples were dried in a vacuum oven at $40^{\circ} \mathrm{C}$ for $24 \mathrm{~h}$ and coated with a $5 \mathrm{~nm}$ silver layer. 
Two types of images were analyzed: the cross section of samples fractured in liquid nitrogen and the internal skin of membrane samples previously cut open using a scalpel. To obtain an accurate representation of membrane morphology, a set of at least 6 images was recorded for each condition investigated.

\section{Results and discussion}

\subsection{Membrane surface characterization}

We report in Figure 3 the $\mathrm{pH}$ dependence of the streaming current coefficient (i.e. the slope of the straight line obtained when measuring streaming current at various pressure differences) for both pristine and aged membranes. Aged membranes appeared to be more negatively charged than pristine membranes, whatever the $\mathrm{pH}$.

In a previous study it was confirmed thanks to a multiscale analysis, that hypochlorite exposure induces PVP radical degradation and dislodgment from the PES matrix [15, 16, 27]. In this work [15], atomic percentages obtained by XPS analysis of the active layer of pristine and hypochlorite treated membranes at $\mathrm{pH} 8$ showed a small increase of oxygen in $\mathrm{NaClO}$ treated membrane which can be ascribed to the formation of small amounts of $\mathrm{COOH}$ (carboxylic acid)/ $/ \mathrm{COO}^{-}$(carboxylate groups) resulting from hydrolysis and ring opening of PVP [4, 27]. Moreover, results obtained by Pruhlo et al. [27] suggest that in the conditions investigated the only degradation undergone by PES results from oxidation of the aromatic ring to form an ortho-substituted phenol [27] with no chain scission.

As a consequence, the increase in the negative charge density of aged membranes shown in Figure 3 (more negative streaming current coefficients) is likely to result from the presence of carboxylic acid groups formed during PVP degradation. These results are in good agreement with the ones of Wolff and Zydney [14] who observed an increase of the negative charge on hypochlorite treated PSf/PVP membrane surface and attributed this increase to the formation of $\mathrm{COO}^{-}$groups resulting from PVP ring opening. Arkhangelsky et al. [9] also reported a negative charge density on the surface of PES/PVP flat membranes accentuated by the contact with $\mathrm{NaClO}$ but these authors ascribed the increase in the negative charge density of aged membranes to the partial scission of the $\mathrm{Ph}-\mathrm{S}$ bond in PES and formation of charged $\mathrm{PhSO}_{3}{ }^{-}$ groups.

Figure 3: Streaming current coefficient $\left(I_{s} / \Delta P\right)$ of pristine and aged membranes as a function of $\mathrm{pH}$.

Contact angle measurements by using captive bubble method were conducted on the inner surfaces of pristine and aged membranes. Similar values in the order of $75 \pm 5^{\circ}$ were obtained for all samples.

Considering PVP dislodgment from the PES matrix, we could expect a decrease in hydrophilicity of the membrane surface. The unmodified contact angle obtained in this study contradicts this assumption. One possible explanation is the partial ionization of the membrane surface due to PVP/PES degradation as demonstrated by streaming current measurements (Fig 3). This formation of charged compounds increases the hydrophilic character of the membrane material compensating PVP dislodgment. Evolution of contact 
angle on aged membrane was also studied by Arkhangelsky et al. [9] by using the sessile drop method. These authors observed a noticeable decrease in contact angle that they ascribed not only to the formation of ionizable groups but also to the formation of bigger pores responsible of spreading out of the drop by capillary. In this case it is very difficult to conclude to an increase in $\mathrm{NaClO}$ treated membrane surface hydrophilicity. The use of the captive bubble method in the present study allowed to avoid measurement artifact due to the porosity evolution.

\subsection{Pristine and aged membrane selectivity curves}

To obtain the membrane retention $R_{m}$ for each Dextran fraction, filtrations of the T500 Dextran solution were carried out for different TMP: $0.4,0.5,0.55$ and 0.6 bar. The calculation of $R_{m}$ is feasible for new and submerged membranes up to $24 \mathrm{~h}$ in $\mathrm{NaClO}$. For longer soaking durations and thus more advanced degradation (results not reported in this paper), the TMP increase leads to a major fouling during Dextran filtration and the calculation of $R_{m}$ by the use of film law is not applicable anymore.

Figure 4: selectivity curve of pristine and aged membrane samples

The calculation of $R_{m}$ for given molar masses of Dextran allows the selectivity curve $R_{m}$ $=\mathrm{f}\left(M_{\text {Dext }}\right)$ (Fig 4) to be obtained, which can be considered as characteristic of the membrane porous structure. The Molecular Weight Cut-Off (MWCO) was determined at $90 \%$ retention. MWCO obtained are:

- $\quad 300 \mathrm{~kg} \cdot \mathrm{mol}^{-1}\left(R_{h y d}=17.94 \mathrm{~nm}\right)$ for pristine membrane

- $500 \mathrm{~kg} \cdot \mathrm{mol}^{-1}\left(R_{\text {hyd }}=22.84 \mathrm{~nm}\right)$ for aged membrane soaked $2 \mathrm{~h}$ in $\mathrm{NaClO}$ (350 ppm, $\mathrm{pH} 8)$

- $1100 \mathrm{~kg} \mathrm{~mol}^{-1}\left(R_{h y d}=33.18 \mathrm{~nm}\right)$ for aged membrane soaked $4 \mathrm{~h}$ in $\mathrm{NaClO}$ (350 ppm, $\mathrm{pH} 8$ )

In the case of a soaking duration of $24 \mathrm{~h}$, the cutoff threshold was not reached in the range of molar masses studied.

In parallel, we measured for each module (pristine and aged ones) the pure water permeability $\frac{L_{P}}{\mu_{20}}$ at 3 different stages: on virgin membrane, on membrane after filtration of the T500

Dextran solution and after back-washing with ultrapure water (15 min - TMP $=1.0$ bar $)$. The results are reported in figure 5 .

Figure 5: pure water permeability of pristine and aged membrane samples, before and after Dextran filtration test and after back-washing with ultrapure water

Permeability values obtained on membranes before Dextran filtration show that contact with hypochlorite $350 \mathrm{ppm} \mathrm{pH} 8$ induced a gradual increase in water transfer through the membrane. For more advanced degradation (longer soaking duration: $144 \mathrm{~h}$, not shown), water permeability is about twice the initial pure water permeability $[15,16]$. It has been shown in previous work that hypochlorite exposure induces PVP radical degradation and 
dislodgment from the PES matrix, leading not only to an increase of the pure water permeability but also to an embrittlement of the membrane [16].

Values obtained after Dextran filtration showed that, regardless of the progress of the membranes degradation, permeability decreased by comparison to the initial one and that fouling responsible for this decrease was hydraulically irreversible (no permeability recovery after back-washing). The loss of permeability induced by the filtration of T500 Dextran was of $12 \%$ for pristine membranes, between $21 \%$ and $31 \%$ for membranes soaked in $\mathrm{NaClO}$ for 2 $\mathrm{h}$ to $24 \mathrm{~h}$; about $45 \%$ was reached for longer soaking ( $144 \mathrm{~h}$; results not shown). These values reflect a fouling amplified for prolonged immersions. According to our protocol (based on the AFNOR standard [28]), permeability losses can reach $30 \%$ while still being reliable and fouling effect on selectivity considered as not significant. The determination of $R_{m}$ was then considered reliable with our method for soaking times in $\mathrm{NaClO}$ ranging from 0 to $24 \mathrm{~h}$.

The origin of this increasing propensity to fouling could be ascribed to chemical changes of the membrane surface, mainly membrane hydrophobic character increase; but also to structural modifications of membrane selective skin; both induced by PVP dislodgment.

This increase in membrane fouling after exposure to $\mathrm{NaClO}$ has been already underlined by several authors [9, 12 and 13]. Arkhangelsky et al. [9] and Levitsky et al. [13] showed that a $\mathrm{NaClO}$ treated PES membrane exhibited an enhanced tendency to fouling with rising hypochlorite concentration leading to an increase in BSA, Dextrans and PEG molecules retention in spite of an enlargement of membrane pores size. They suggested that the increased hydrophilicity of membrane surface induced by ionizable groups formation enhanced the adsorption of these molecules. This point is questionable if we admit that hydrophobic solutes such as certain proteins less adsorb on hydrophilic surface. Levitsky et al. [13] concluded that permeation tests (water permeability and tracers retention) being influenced by hydrophilicity, the interpretation of the results is subjective and the previously reported enlargement of pore size (i.e. [14]) is an artifact related to the employed pore size tests.

In order to ensure a proper membrane selectivity characterization, one can agree that it is necessary to develop test protocol that enables the minimization of fouling during the tracer's filtration. In this purpose the choice of Dextran as tracer molecule has been already evaluated. Wolff and Zydney [14] validated their characterization protocol using Dextrans by performing two series of experiments. They first characterized a PSf/PVP membrane after exposure to bleach for $0.5 \mathrm{~h}$, and after subsequent incremental treatment for total bleach exposures of 1,5 and $14 \mathrm{~h}$. In the second series, experiments were preformed with a single continuous $14 \mathrm{~h}$ exposure to hypochlorite. The authors obtained after $14 \mathrm{~h}$ exposure in both cases identical data, indicating that intermediate Dextran filtration in the first series had no effect on membrane selectivity.

In the present study, it can be noticed that the AFNOR standard [28], recommending a maximum permeability loss of $30 \%$ during filtration of a tracer solution, was respected in the case of soaking duration shorter or equal to 24 hours. In these treatment conditions and following the proposed protocol we then considered that Dextran membrane retention $R_{m}$ provided us a satisfactory characterization of the intrinsic selectivity of the membrane in normal conditions of use.

\subsection{Pore size distribution of pristine membrane}


The parameters of the initial log-normal pore size distribution leading to calculated permeability and selectivity were first determined as close as possible of the experimental results.

SEM observations of the inner surface of the pristine membrane do not provide evidence of apparent pore size exceeding $40 \mathrm{~nm}$ in radius (Fig 6). It should be noted that the pores are aligned and relatively close to each other (i.e. the distance between two adjoining pores is less than one pore diameter).

Figure 6: SEM image of the inner surface of the pristine membrane

Moreover, bubble point measurements were carried out on membrane samples presenting an internal surface of approximately $10^{-3} \mathrm{~m}^{2}$ to estimate the size of the biggest pores of the selective skin. The resulting pressures were:

-for pristine membranes: $\mathrm{P}_{\mathrm{b}}=3.90 \pm 0.09$ bar.

-for aged membranes $(24 \mathrm{~h}): \mathrm{P}_{\mathrm{b}}=2.84 \pm 0.32$ bar.

Considering that at least one bubble was observed at these pressures on each membrane sample tested, we assumed that the number of big pores was equal or higher to 1000 per $^{2}$ of membrane.

As already mentioned, these tests have been completed with contact angle measurements on inner surface of pristine and aged membranes. Similar values in the order of $75 \pm 5^{\circ}$ were collected for all samples. This allows us to estimate $r_{\max }$ by using Eq. 11 to approximately 97 $\mathrm{nm}$ for the pristine membrane and $133 \pm 15 \mathrm{~nm}$ for the aged ones.

Concerning the thickness (l) of the membrane selective skin, no characterization technique enables to precisely determine it. We will therefore set this parameter to an arbitrary value of $0.1 \mu \mathrm{m}$, which corresponds to an order of magnitude commonly consider for asymmetric UF membrane.

For an estimation of the pore size distribution of pristine membranes, we have therefore selected for the two parameters $r_{\text {pore }}$ (maximum of the log-normal function) and $\sigma$ (geometric standard deviation of the function) values meeting the following conditions: $r_{\text {pore }}$ $<40 \mathrm{~nm}$, according SEM observations, and $r_{\max }<100 \mathrm{~nm}$, with $r_{\max }$ defined as the maximum value of $r_{i}$ for which $n\left(r_{i}\right)>1000$ pores $\mathrm{m}^{-2}$.

Fitting of $r_{\text {pore }}$ and $\sigma$ were conducted by minimizing the sum of the square of the differences between the experimental data points and the predicted values of $R_{m}$ (at specific values of $R_{\text {hyd }}$ ranging from $10 \mathrm{~nm}$ to $40 \mathrm{~nm}$ ), while the fitting of $N_{\text {pore }}$ was done by minimizing the square of the difference between the experimental and the calculated permeability. It was thus possible to obtain the following parameters of the log-normal distribution, corresponding to the best correlation between calculated and experimental pristine membrane properties:

$$
r_{\text {pore }}=17.5 \mathrm{~nm}, \quad \quad \sigma=0.25, \quad N_{\text {pore }}=2.8110^{12} \text { pores }^{-2}
$$

This distribution leads to a calculated permeability of $623 \mathrm{~L} \mathrm{~h}^{-1} \mathrm{~m}^{-2} \mathrm{bar}^{-1}$, which has to be compared to the experimental value of $628 \pm 50 \mathrm{~L} \mathrm{~h}^{-1} \mathrm{~m}^{-2} \mathrm{bar}^{-1}$ (deduced from an average of at least 10 measurements). Concerning the membrane selectivity, calculated membrane retention coefficients depicted in figure 7 , a are very similar to those obtained experimentally. Figure 
$7, \mathrm{~b}$ also offers a representation of $n(r)$ the discontinuous distribution of the number of pores and of $J(r)$ the flow density relative to each pore size class. Such a distribution of pore sizes shows a $r_{\text {max }}$ of $96 \mathrm{~nm}$ (not visible on figure $7, \mathrm{~b}$ ).

Figure 7: (a) Calculated and experimental selectivity curves for pristine membrane and (b) $n(r)$ the discontinuous distribution of the number of pores and $J(r)$ the flow density relative to each pore size class

\subsection{Scenarios of pore size distribution evolution of aged membranes}

As mentioned in the introduction, a previous study conducted by Pellegrin et al. [16] showed that hypochlorite exposure induces radical degradation of PVP (involving PVP chain scissions) and its dislodgement from the PES matrix, leading to an increase in the pure water permeability and to the embrittlement of the PES/PVP membrane. A direct relationship between the changes in permeability and in the PVP ATR-FTIR band intensity was established. For the early stages of the degradation, results showed that the decrease in PVP ATR-FTIR band corresponds to an increase in permeability, meaning that the PVP removal from the membrane material leads to an increase of the accessible porosity in the active layer. As the degradation was more advanced, beyond around $50 \mathrm{~h}$ exposure in $\mathrm{NaClO} 350 \mathrm{ppm}$ at $\mathrm{pH} 8$, the permeability reached a plateau. The assumption was made that beyond a given hypochlorite dose, the degradation and dislodgment of the majority of the PVP accessible within the selective layer (within a thickness of 10-100 nm) has occurred.

Several scenarios of evolution of the membrane selective layer thickness and pore size distribution have been considered to explain the changes observed in selectivity and permeability. Among the scenarios investigated, we have considered separately or simultaneously the decrease of the selective layer thickness (i.e. decrease of the pore length), the shift of the initial pore size distribution (i.e. increase of pore radius induced by erosion) and the formation of a second population of pores of larger sizes (appearance of defects) with or without modification of the initial pore size distribution.

The results showed that the decrease of the pore length has almost no influence on the calculated selectivity and permeability. This is obvious when considering the equations 6 and 7. Equation 6 shows that a pore radius change (to the power 4) will have much greater impact on the calculated permeability than a pore length modification (to the power -1). Equation 7 shows that, $1 / \mathrm{J}$ being proportional to the membrane selective layer thickness; by simplification the pore length does not appear in the calculation of the retention.

When we considered that ageing leads to the formation of a second population of pores of larger sizes without modification of the initial pore size distribution, the calculated retention was only modified for high molecular weight tracers without effect on small ones, which was not consistent with experimental results.

Among the scenarios investigated, the two scenarios reported here below are the only ones allowing to reach a satisfactory correlation between calculated and experimental transfer properties.

Given that membrane degradation hypochlorite induced mainly resulted in a gradual dislodgement and departure of PVP from the PES matrix, and assuming that PVP is homogeneously distributed in the structure of the selective skin, we first considered that the 
radius of each pore class increased during ageing. To model this scenario, we assumed that, throughout the degradation:

- The radius of all pores increased to the same extent $e$ resulting from the pore wall degradation.

- $\quad N_{\text {pore }}$ and $\sigma$ (the parameters of the log-normal distribution of the pristine membrane) remain unchanged.

- The active layer thickness of the membrane remains unchanged.

The equations presented earlier, allowing the calculation of the permeability and intrinsic retention, then become:

$$
\frac{L_{P}}{\mu_{20}}=\sum_{i} \frac{\pi}{8 \mu_{20} l} n\left(r_{i}\right)\left(r_{i}+e\right)^{4}
$$

and

$$
R_{m}=\frac{1}{J} \sum_{i} \frac{\pi n\left(r_{i}\right)\left(r_{i}+e\right)^{4}\left(1-\left(1-\frac{R_{h y d}}{\left(r_{i}+e\right)}\right)^{2}\right)^{2}}{8 \mu_{20} l}
$$

As shown in figure 8 , by varying the thickness $e$, we thus obtained calculated values of $R_{m}$, corresponding to the different levels of degradation $(2,4$ and $24 \mathrm{~h})$ for which we were able to obtain the experimental intrinsic selectivity curve of the membrane (section 4.2). We identified the following changes in pore radius as a function of hypochlorite exposure time:

- $\quad \mathrm{NaClO} 350 \mathrm{ppm}, \mathrm{pH} 8-2 \mathrm{~h}: e_{2 h}=8 \mathrm{~nm}$

- $\quad \mathrm{NaClO} 350 \mathrm{ppm}, \mathrm{pH} 8-4 \mathrm{~h}: e_{4 h}=18 \mathrm{~nm}$

- $\quad \mathrm{NaClO} 350 \mathrm{ppm}, \mathrm{pH} 8-24 \mathrm{~h}: e_{24 h}=44 \mathrm{~nm}$.

The pore size distributions corresponding to calculated retention for the various membrane samples were obtained by keeping $N_{\text {pore }}$ and $\sigma$ constant and modifying only the radius parameter. The theoretical permeabilities deduced from such changes in pore radii are reported in table 1 . Obviously the pore size distribution is shifted to the higher size. Although this scenario of the evolution of the pore size distribution allows us to satisfactorily model the evolutions of $R_{m}$, theoretical permeabilities are not consistent with the values obtained experimentally as shown in Table 1.

Figure 8 Selectivity curves of pristine and aged membranes ( $\mathrm{NaClO} 350 \mathrm{ppm}, \mathrm{pH} 8)$, comparison between experimental results and calculated ones using a pore size distribution in which ageing induced an increase in pore radius (first scenario).

The first scenario, based on the sole shifting of the pore-size distribution towards wider pore radii, therefore fails to provide a sound explanation to the observed modifications of the membrane performance after exposure to hypochlorite.

It is worth mentioning, however, that the approach considered in the present work to calculate the membrane permeability (Eq 6) only takes into account the hydraulic resistance of the membrane skin layer and disregards the hydraulic resistance of the support, the latter being assumed very low. Due to membrane skin degradation and the subsequent increase of its hydraulic permeability, the hydraulic resistance of the support could become non negligible during degradation as compared to the one of the degraded selective skin. 
Table 1: experimental and calculated permeabilities $\frac{L_{P}}{\mu_{20}}$ of pristine and aged membranes according the first scenario

The second scenario investigated involves the formation of a second population of pores in membrane skin structure of larger sizes called "defects". In the same way as for the initial pore size distribution, the size of these defects are assumed to be represented by a log-normal distribution $n_{d}(r)$, with the parameters $r_{\text {defect }}, \sigma_{d}$ and $N_{\text {defect }}$. During the degradation process, we assume that the departure of the PVP causes an enlargement of the initially present pores, with "fusion" of some of them, leading to the outbreak of a new population of pores of larger radius (defects). We used here the word "fusion" to name the phenomenon corresponding to the disappearance of the wall between two adjoining pores following polymer degradation. This assumption is consistent with the distance between two pores which is less than one pore diameter (less than $40 \mathrm{~nm}$ ) and the extent of the pore radius increase $e$ considered (between 8 and $44 \mathrm{~nm}$ ). Moreover, we assume that the new population of pores cannot be the own pores of the support layer which turns up due to PVP dislodgment as the skin layer remains substantially denser than the membrane bulk, which presents a spongy structure with macro-voids (observed by cross-section SEM imaging not shown here).

The assumption of the "fusion" of some pores during ageing leads to a decrease in the total number of pores of the initial distribution $N_{\text {pore }}$. We represent this phenomenon by a shift of the maximum of the initial distribution to larger pores (increase of $r_{\text {pore }}$ ), accompanied by a reduction of $N_{\text {pore }}$, keeping $\sigma$ constant. The latter assumption is consistent with the fact that the decrease in $N_{\text {pore }}$ is quite negligible by comparison to the initial total number of pores. Iterative steps were employed to adjust $n(r)$ and $n_{d}(r)$ parameters in order to obtain the best agreement between calculated and experimental membrane retentions and permeabilities. Tables 2 and 3 and figures 9 and 10 show the results obtained according this scenario.

Table 2 - Parameters of the log-normal pore size distributions of pristine and aged membranes according to the second scenario

Table 3 - experimental and calculated permeabilities $\frac{L_{P}}{\mu_{20}}$ of pristine and aged membranes according to the second scenario

Figure 9: Selectivity curves of pristine and aged membranes ( $\mathrm{NaClO} 350 \mathrm{ppm}, \mathrm{pH} 8$ ), comparison between experimental results and calculated ones according to the second scenario.

Figure 10: a) $n(r)$ the discontinuous distribution of the number of pores and of defects and b) $J(r)$ the flow density relative to each pore size class for pristine and aged membrane samples according the second scenario 
The reported results demonstrated that the second scenario led to a good agreement between experimental and calculated values for both retentions and permeabilities of aged membranes after different exposure times to sodium hypochlorite.

The evolutions of the membrane transfer properties over its hypochlorite-induced ageing could then be modeled by increasing the pore radius of the initial population, accompanied by a decrease in their number, and coupled with the appearance of defects, whose radius increases with the progress of the degradation. The relevance of a scenario involving the emergence of a defects population of larger sizes than those of the initial pore distribution was also supported by surface analyses. In a previous work, Prulho [29] has performed a 2D mapping by ATR - IRTF of the inner surface of the membranes used in the present paper. This study showed a heterogeneous surface distribution of PVP with areas at high PVP concentration reaching several tens of $\mu \mathrm{m}^{2}$ (Fig 11). The dislodgment of the PVP in these areas could reasonably lead to the formation of defects. The SEM image of the pristine membrane (Fig 6) also shows that some pores are very close each other and so could merge easily from the membrane degradation.

Figure 11: 2D mapping by ATR - IRTF of the inner surface of pristine membrane showing the amide band intensity of PVP (from Prulho [29])

\section{Conclusion}

In this work PES/PVP membranes underwent a static accelerated ageing protocol, by exposure to a $350 \mathrm{ppm} \mathrm{NaClO}$ solution at $\mathrm{pH} 8$ for several hours, ranging from $2 \mathrm{~h}$ to $24 \mathrm{~h}$. This study demonstrated that chemical and structural changes of the selective skin of membranes during their exposure to sodium hypochlorite greatly affected membrane filtration performance, perceived by changes in both permeability and selectivity properties compared to pristine membrane results.

In the conditions investigated in this work, aged membranes had permeability values up to 1.6 times greater than the pristine membrane.

In parallel, the transfer of soluble polymers (Dextran) across the membrane increased substantially with the increase of hypochlorite exposure time, reflecting a rapid alteration of the selectivity of the membrane during hypochlorite soaking at $\mathrm{pH} 8$. Changes in pure water permeability were also investigated by comparing the initial values with the ones achieved after retention tests and after a backwashing procedure. It has been shown that the water flux after Dextran filtration decreased by comparison to the initial one with a loss all the more important that the degradation was advanced. The fouling inducing this permeability decrease was hydraulically irreversible as no permeability recovery was obtained after backwashing. The membrane material was then more sensitive to fouling after ageing, even towards soluble polymers like neutral Dextrans, well-known for their negligible interactions with this type of membrane material. In this context, operating conditions and procedure minimizing fouling during membrane characterization were sought in order to reach intrinsic membrane selectivity. Membrane retention was then successfully calculated for pristine and aged samples using the film model in the cases of soaking duration shorter or equal to 24 hours in $\mathrm{NaClO} 350 \mathrm{ppm}$ pH8. 
A numerical study was implemented to propose a scenario of the evolution of the pore size distribution leading to the permeability and retention values obtained experimentally on aged membranes. The initial pore size distribution of pristine membrane was assimilated to a monomodal lognormal distribution. The most probable scenario of distribution evolution over degradation process was then an increase of the pore radius of the initial population, accompanied by a decrease in their number, coupled with the appearance of defects, whose radius increased with the progress of the degradation. It was assumed that the appearance of theses defects partially originated from the "fusion" of initially present pores.

\section{Acknowledgements}

Financial support from the French National Research Agency is gratefully acknowledged (project $\mathrm{n}^{\circ}$ ANR-09-BLAN-0055-01). The authors also wish to thanks the partners of this project for their contribution: Pr J.L. Gardette, Dr A. Rivaton, Dr S. Thérias and R. Prulho, Blaise Pascal University (Clermont-Ferrand, France); Pr M. Rabiller-Baudry, University of Rennes (France) and Dr E. Gaudichet-Maurin, Veolia Environment Research and Innovation (Maisons-Laffitte, France). 


\section{References}

[1] N. Porcelli, S. Judd, Chemical cleaning of potable water membranes: A review, Separation and Purification Technology 71 (2010) 137-143.

[2] A.J. Gijsbertsen-Abrahamse, E.R. Cornelissen, J.A.M.H. Hofman, Fiber failure frequency and causes of hollow fiber integrity loss, Desalination 194 (2006) 251-258.

[3] R. Baker, Membrane Technology and Applications, Wiley, 2004.

[4] I.M. Wienk, E.E.B. Meuleman, Z. Borneman, T. Boomgaard, Chemical treatment of membranes of a polymer blend: Mechanism of the reaction of hypochlorite with poly(vinyl pyrrolidone), Journal Polymer Science 33 (1995) 49-54.

[5] J.J. Qin, M.H. Oo, Y. Li, Development of high flux polyethersulfone hollow fiber ultrafiltration membranes from a low critical solution temperature, Journal of Membrane Science 247 (2005) 137-142.

[6] L. Bégoin, M. Rabiller-Baudry, B. Chaufer, M.C. Hautbois, T. Doneva, Ageing of PES industrial spiral-wound membranes in acid whey ultrafiltration, Desalination 192 (2006) 2539.

[7] F. Thominette, O. Farnault, E. Gaudichet-Maurin, C. Machinal, J.C. Schrotter, Ageing of polyethersulfone ultrafiltration membranes in hypochlorite treatment, Desalination 200 (2006) 7-8.

[8] E. Zondervan, A. Zwijnenburg, B. Roffel, Statistical analysis of data from accelerated ageing tests of PES UF membranes, Journal of Membrane Science 300 (2007) 111-116.

[9] E. Arkhangelsky, D. Kuzmenko, V. Gitis, Impact of Chemical Cleaning on Properties and Functioning of Polyethersulfone Membranes, Journal of Membrane Science 305 (2007) 176184.

[10] E. Arkhangelsky, D. Kuzmenko, N.V. Gitis, M. Vinogradov, S. Kuiry, V. Gitis, Hypochlorite cleaning causes degradation of polymer membranes, Tribology Letters 28 (2007) 109-116.

[11] K. Yadav, K.R. Morison, M.P. Staiger, Effects of hypochlorite treatment on the surface morphology and mechanical properties of polyethersulfone ultrafiltration membranes, Polymer Degradation and Stability 94 (2009) 1955-1961.

[12] K. Yadav, K.R. Morison, Effects of hypochlorite exposure on flux through polyethersulfone ultrafiltration membranes, Food and Bioproducts Processing 88 (2010) 419424.

[13] I. Levitsky, A. Duek, E. Arkhangelsky, D. Pinchev, T. Kadoshian, H. Shetrit, R. Naim, V. Gitis, Understanding the oxidative cleaning of UF membranes, Journal of Membrane Science 377 (2011) 206-213. 
[14] S.H. Wolff, A.L. Zydney, Effect of Bleach on the Transport Characteristics of Polysulfone Hemodialyzers, Journal of Membrane Science 243 (2004) 389-399.

[15] B. Pellegrin, E. Gaudichet-Maurin, C. Causserand, Mechano-chemical ageing of PES / PVP ultrafiltration membranes used in drinking water production, Water Science \& Technology: Water Supply 13-2 (2013) 541-551.

[16] B. Pellegrin, R. Prulho, A. Rivaton, S. Thérias, J.L. Gardette, E. Gaudichet-Maurin, C. Causserand, Multi-scale analysis of hypochlorite induced PES/PVP ultrafiltration membranes degradation, Journal of Membrane Science 447 (2013) 287-296.

[17] P. Aimar, M. Meireles, V. Sanchez, A contribution to the translation of retention curves into pore size distribution for sieving membranes, Journal of Membrane Science 54 (1990) 321-338.

[18] K.A. Granath, Solution properties of branched dextrans, Journal of Colloid Science 13.4 (1958) 308-328.

[19] R.B. Bird, W.E. Stewart, E.N. Lightfoot, Transport Phenomena, John Wiley \& Sons, New York, 1960.

[20] A.L. Zydney, P. Aimar, M. Meireles, J.M. Pimbley, G. Belfort, Short communication: use of the log-normal probability density function to analyze membrane pore size distributions: functional forms and discrepancies, Journal of Membrane Science 91(1994) 293-298.

[21] L.J. Zeman, A.L. Zydney, Microfiltration and Ultrafiltration - Principles and Applications, Marcel Dekker, New York, 1996.

[22] W.R. Bowen, J. S. Welfoot, Modelling of membrane nanofiltration-pore size distribution effects, Chemical Engineering Science, 57-8 (2002) 1393-1407.

[23] C. Causserand, S. Rouaix, A. Akbari, P. Aimar, Improvement of a method for the characterization of ultrafiltration membranes by measurements of tracers retention, Journal of Membrane Science 238 (2004) 177-190.

[24] Y. Lanteri, P. Fievet, S. Déon, P. Sauvade, W. Ballout, A. Szymczyk, Electrokinetic characterization of hollow fibers by streaming current, streaming potential and electric conductance, Journal of Membrane Science 411-412 (2012) 193-200.

[25] A. Yaroshchuk, T. Luxbacher, Interpretation of Electrokinetic Measurements with Porous Films: Role of Electric Conductance and Streaming Current within Porous Structure, Langmuir 26 (2010) 10882-10889.

[26] A. Szymczyk, Y.I. Dirir, M. Picot, I. Nicolas, F. Barrière, Advanced Electrokinetic Characterization of Composite Porous Membranes, Journal of Membrane Science 429 (2013) 44-51. 
[27] R. Prulho, S. Thérias, A. Rivaton, J.L. Gardette, Ageing of polyethersulfone / polyvinylpyrrolidone blends in contact with bleach water, Polymer Degradation and Stability 98-6 (2013) 1164-1172.

[28] French Standard NF X 45-103 AFNOR Association Française de Normalisation, 1997.

[29] R. Prulho, Blaise Pascal University, Clermont Ferrand, France, 2013 (PhD thesis). 


\section{Figure captions}

Figure 1: Cross-section SEM image of a cryo-fractured pristine membrane

Figure 2: Experimental set-up

Figure 3: Streaming current coefficient $\left(I_{s} / \Delta P\right)$ of pristine and aged membranes as a function of $\mathrm{pH}$.

Figure 4: selectivity curve of pristine and aged membrane samples

Figure 5: pure water permeability of pristine and aged membrane samples, before and after Dextran filtration test and after back-washing with ultrapure water

Figure 6: SEM image of the inner surface of the pristine membrane

Figure 7: (a) Calculated and experimental selectivity curves for pristine membrane and (b) $n(r)$ the discontinuous distribution of the number of pores and $J(r)$ the flow density relative to each pore size class

Figure 8: Selectivity curves of pristine and aged membranes ( $\mathrm{NaClO} 350 \mathrm{ppm}, \mathrm{pH} 8$ ), comparison between experimental results and calculated ones using a pore size distribution in which ageing induced an increase in pore radius (first scenario).

Figure 9: Selectivity curves of pristine and aged membranes ( $\mathrm{NaClO} 350 \mathrm{ppm}, \mathrm{pH}$ 8), comparison between experimental results and calculated ones according to the second scenario

Figure 10: a) $n(r)$ the discontinuous distribution of the number of pores and of defects and b) $J(r)$ the flow density relative to each pore size class for pristine and aged membrane samples according the second scenario

Figure 11: 2D mapping by ATR - IRTF of the inner surface of pristine membrane showing the amide band intensity of PVP (from Prulho [29])

\section{Table captions}

Table 1: experimental and calculated permeabilities $\frac{L_{P}}{\mu_{20}}$ of pristine and aged membranes according the first scenario

Table 2: Parameters of the log-normal pore size distributions of pristine and aged membranes according to the second scenario

Table 3: experimental and calculated permeabilities $\frac{L_{P}}{\mu_{20}}$ of pristine and aged membranes according to the second scenario. 
Table 1: experimental and calculated permeabilities $\frac{L_{P}}{\mu_{20}}$ of pristine and aged membranes according the first scenario

\begin{tabular}{rrrrr}
\hline & \multicolumn{4}{c}{$\frac{L_{P}}{\mu_{20}}\left(\mathrm{~L} \mathrm{~h}^{-1} \mathrm{~m}^{-2} \mathrm{bar}^{-1}\right)$} \\
\cline { 2 - 5 } & $\begin{array}{r}\text { Pristine } \\
\text { membrane }\end{array}$ & $\begin{array}{r}N a O C l 350 \mathrm{ppm} \\
\mathrm{pH} \mathrm{8-2h}\end{array}$ & $\begin{array}{r}\text { NaOCl 350 ppm } \\
\mathrm{pH} \mathrm{8}-4 \mathrm{~h}\end{array}$ & $\begin{array}{r}\text { NaOCl 350 ppm } \\
\mathrm{pH} \mathrm{8}-24 \mathrm{~h}\end{array}$ \\
\hline Experimental values & 628 & 705 & 846 & 1002 \\
Calculated values & 623 & 2435 & 9169 & 110307 \\
\hline
\end{tabular}

Table 2 - Parameters of the log-normal pore size distributions of pristine and aged membranes according to the second scenario 


\begin{tabular}{|c|c|c|c|c|}
\hline & Pristine membrane & $\begin{array}{r}\mathrm{NaOCl} 350 \mathrm{ppm} \\
\mathrm{pH} 8-2 \mathrm{~h}\end{array}$ & $\begin{array}{r}\mathrm{NaOCl} 350 \mathrm{ppm} \\
\mathrm{pH} 8-4 \mathrm{~h}\end{array}$ & $\begin{array}{r}\mathrm{NaOCl} 350 \mathrm{ppm} \\
\mathrm{pH} 8-24 \mathrm{~h}\end{array}$ \\
\hline & \multicolumn{4}{|l|}{ pore size distribution } \\
\hline$r_{\text {pore }}(\mathrm{nm})$ & 17.5 & 19 & 21 & 25 \\
\hline$\sigma$ & 0.25 & 0.25 & 0.25 & 0.25 \\
\hline$N_{\text {pore }}$ & $2.8110^{12}$ & $1.9810^{12}$ & $1.1310^{12}$ & $0.1410^{12}$ \\
\hline \multicolumn{5}{|c|}{ defect size distribution } \\
\hline$r_{\text {defect }}(\mathrm{nm})$ & - & 40 & 48 & 66 \\
\hline$\sigma_{d}$ & - & 0.1 & 0.12 & 0.15 \\
\hline$N_{\text {defect }}$ & - & $3.9010^{10}$ & $4.2010^{10}$ & $3.0010^{10}$ \\
\hline
\end{tabular}

Table 3 - experimental and calculated permeabilities $\frac{L_{P}}{\mu_{20}}$ of pristine and aged membranes according to the second scenario

\begin{tabular}{rrrrr}
\hline & & & & $\frac{L_{P}}{\mu_{20}}\left(\mathrm{~L} \mathrm{~h}^{-1} \mathrm{~m}^{-2} \mathrm{bar}^{-1}\right)$ \\
\cline { 2 - 5 } & $\begin{array}{r}\text { Pristine } \\
\text { membrane }\end{array}$ & $\begin{array}{r}\text { NaOCl 350 ppm } \\
\mathrm{pH} \mathrm{8-2} \mathrm{h}\end{array}$ & $\begin{array}{r}\text { NaOCl 350 ppm } \\
\mathrm{pH} \mathrm{8-4h}\end{array}$ & $\begin{array}{r}\text { NaOCl 350 ppm } \\
\mathrm{pH} \mathrm{8-24} \mathrm{h}\end{array}$ \\
\hline Experimental values & 628 & 705 & 846 & 1002 \\
Calculated values & 623 & 764 & 877 & 1105 \\
\hline
\end{tabular}


Highlights of the work

Effect of membrane ageing on model solute filtration was studied Modifications in membrane characteristics were correlated to selectivity evolution Membrane degradation has an effect on solute-membrane interaction and lowered selectivity Scenarios of pore size distribution evolution over degradation process were proposed 


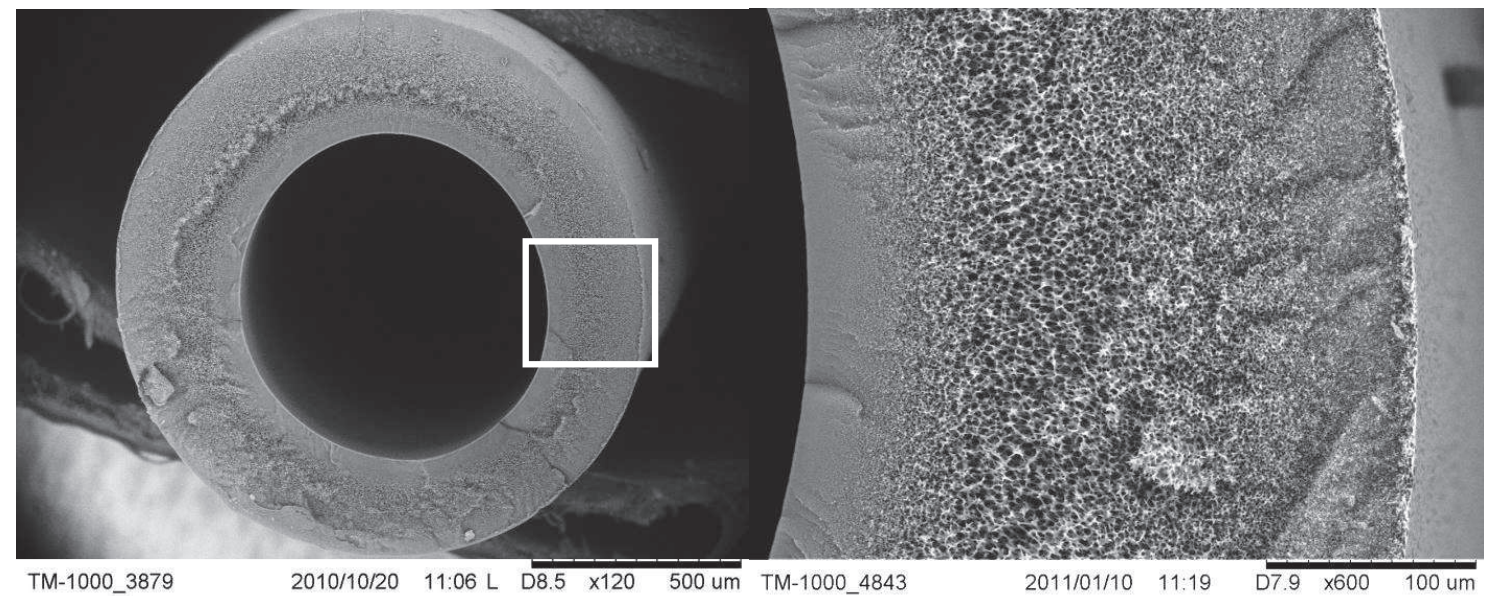

Figure 1: Cross-section SEM image of a cryo-fractured pristine membrane 


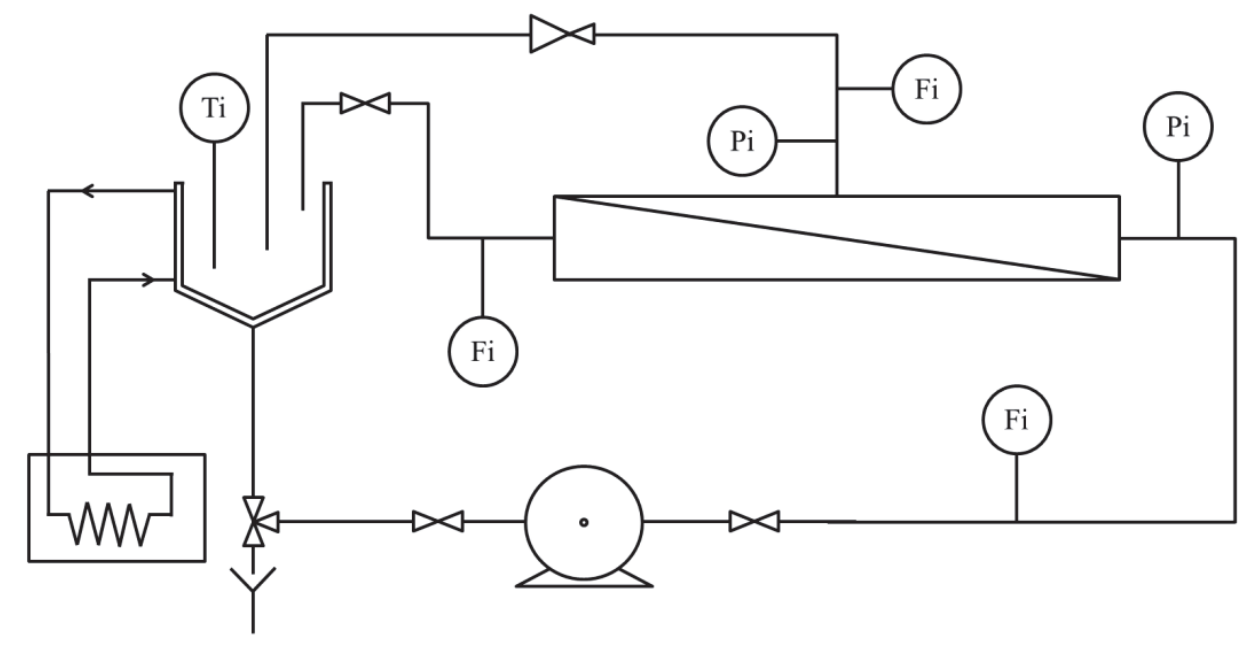

Figure 2: Experimental set-up 


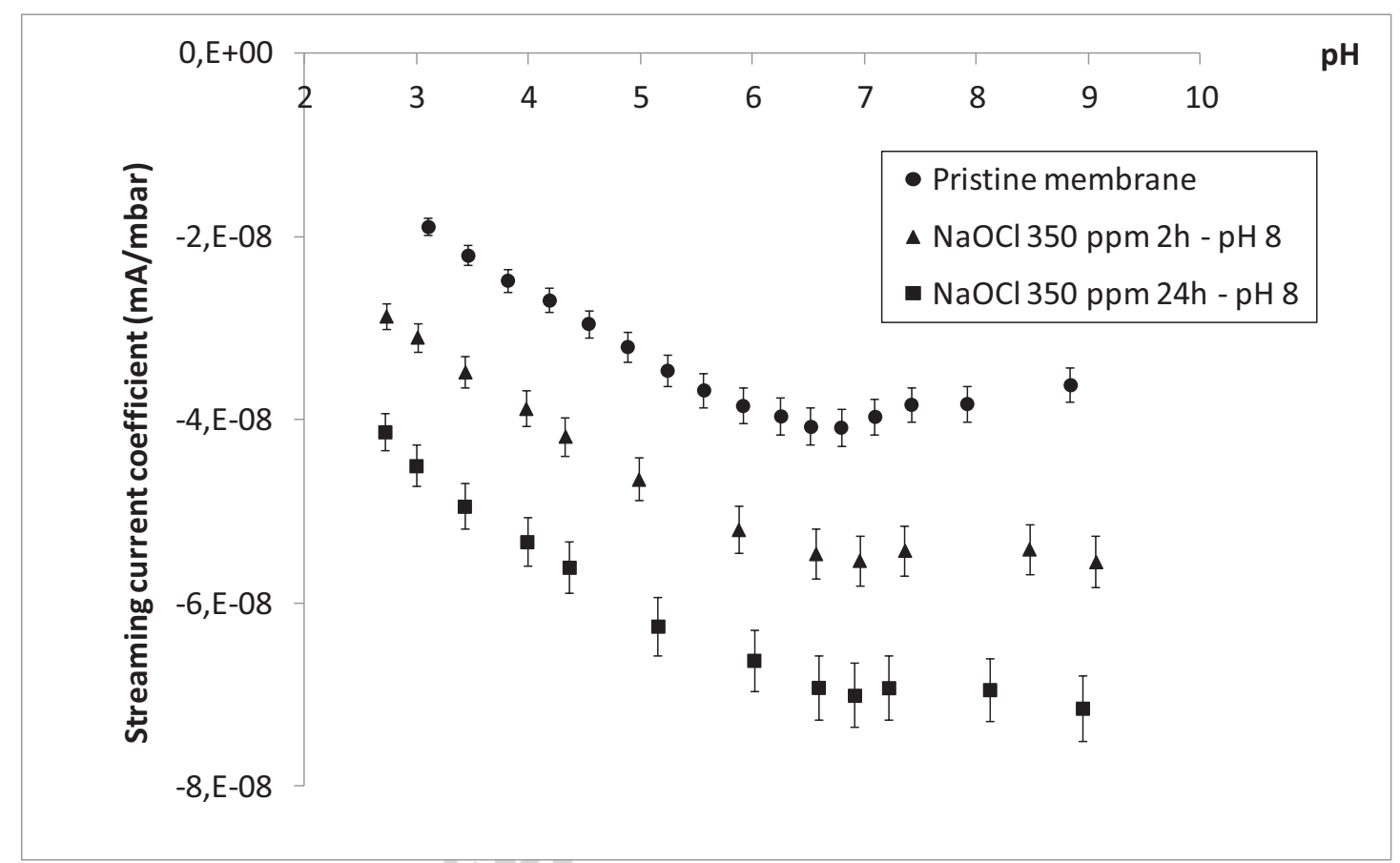

Figure 3: Streaming current coefficient $\left(\mathrm{I}_{\mathrm{s}} / \Delta \mathrm{P}\right)$ of pristine and aged membranes as a function of $\mathrm{pH}$. 


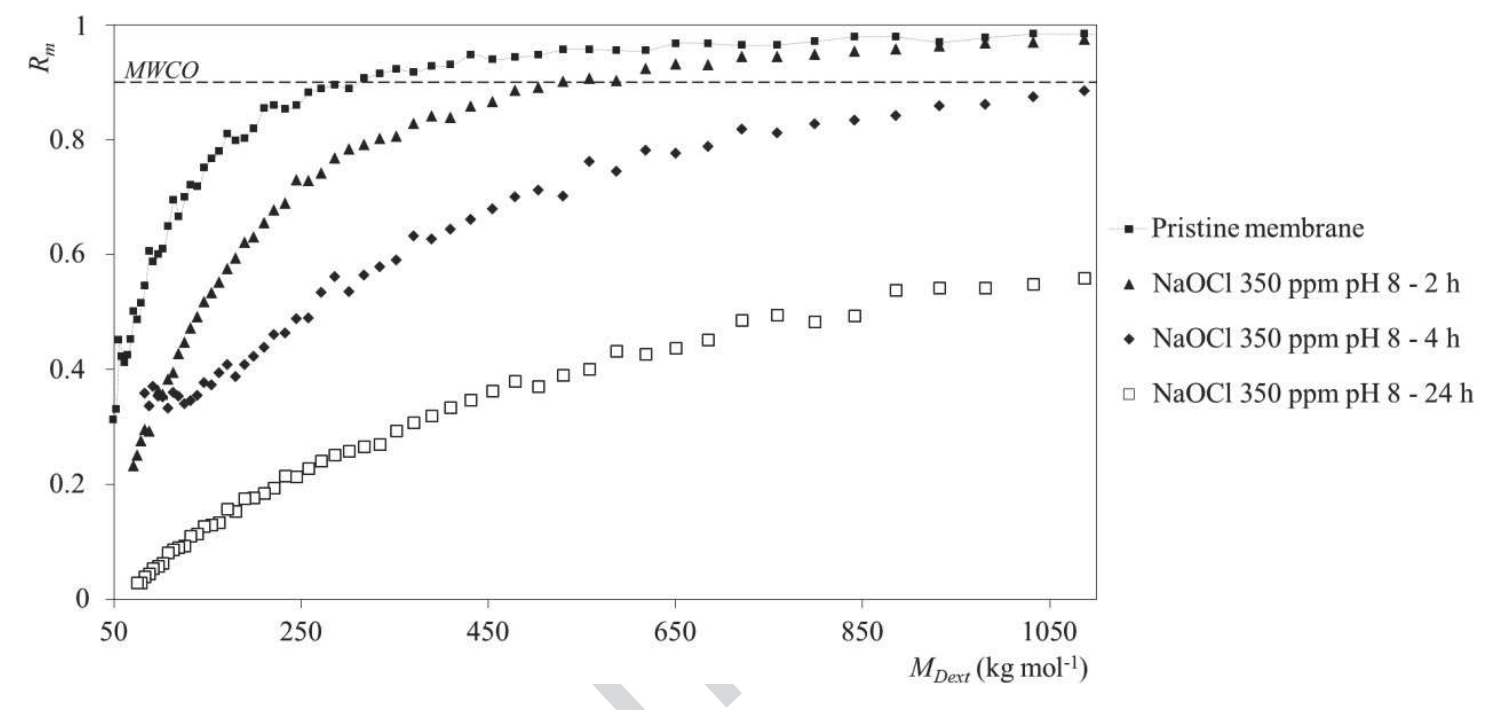

Figure 4: selectivity curve of pristine and aged membrane samples 


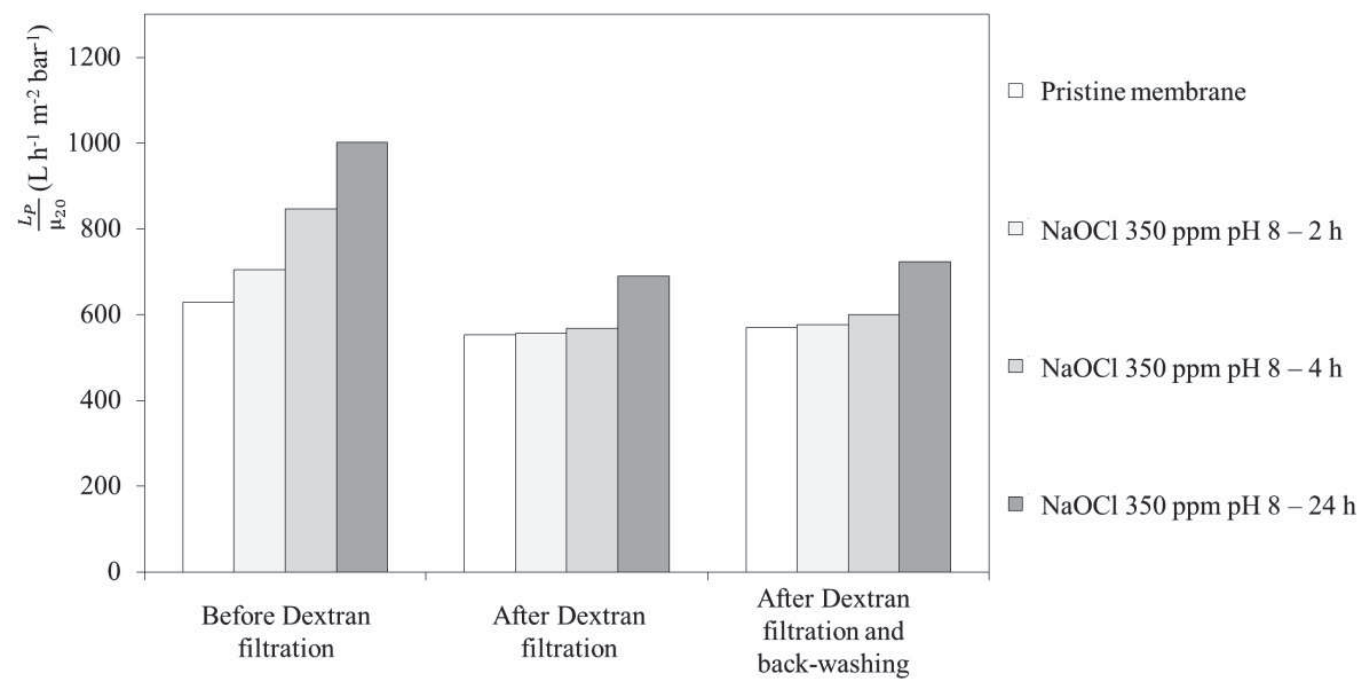

Figure 5: pure water permeability of pristine and aged membrane samples, before and after Dextran filtration test and after back-washing with ultrapure water 


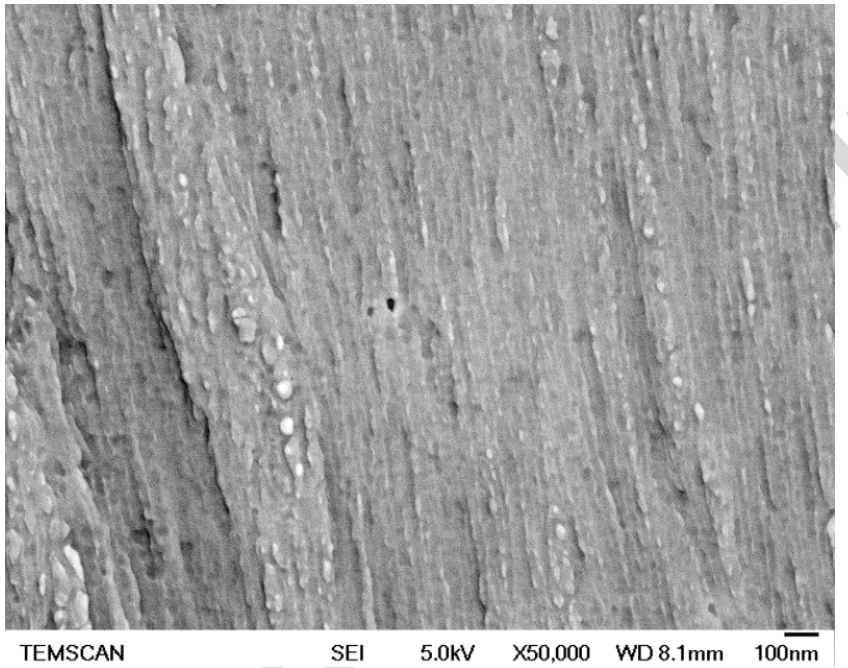

Figure 6: SEM image of the inner surface of the pristine membrane 
a)

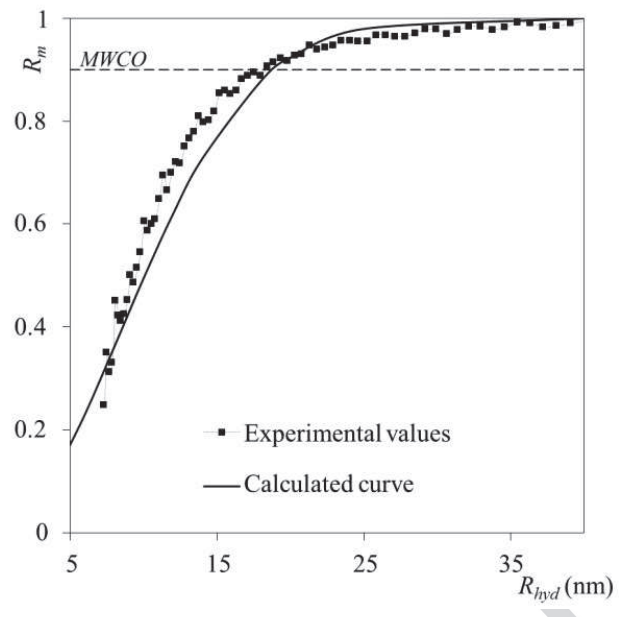

b)

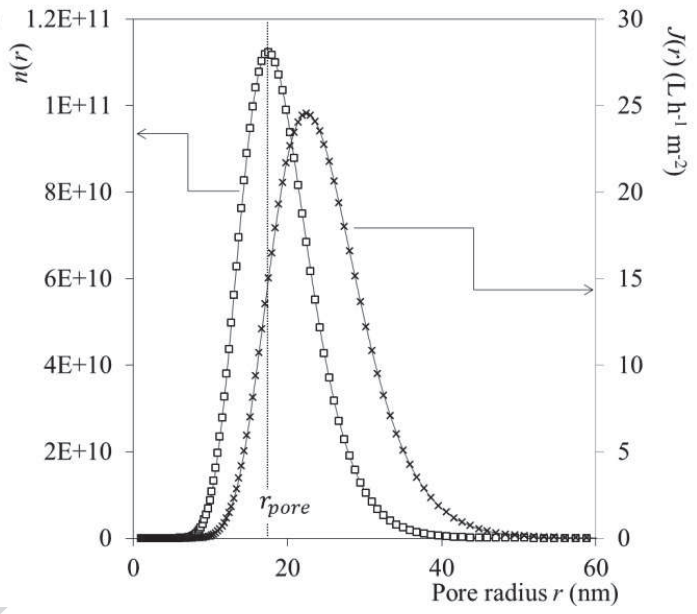

Figure 7: (a) Calculated and experimental selectivity curves for pristine membrane and (b) $n(r)$ the discontinuous distribution of the number of pores and $J(r)$ the flow density relative to each pore size class 


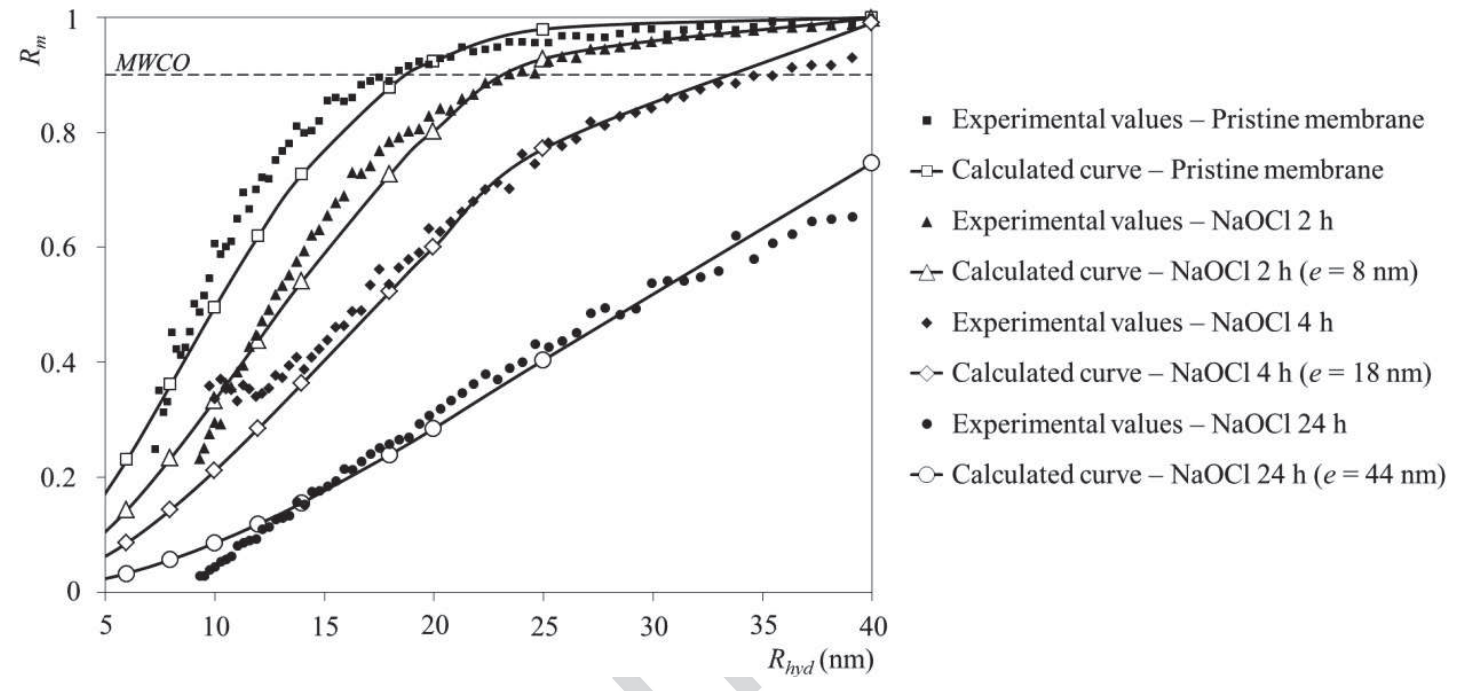

Figure 8 Selectivity curves of pristine and aged membranes ( $\mathrm{NaOCl} 350 \mathrm{ppm}, \mathrm{pH} \mathrm{8})$, comparison between experimental results and calculated ones using a pore size distribution in which ageing induced an increase in pore radius (first scenario). 


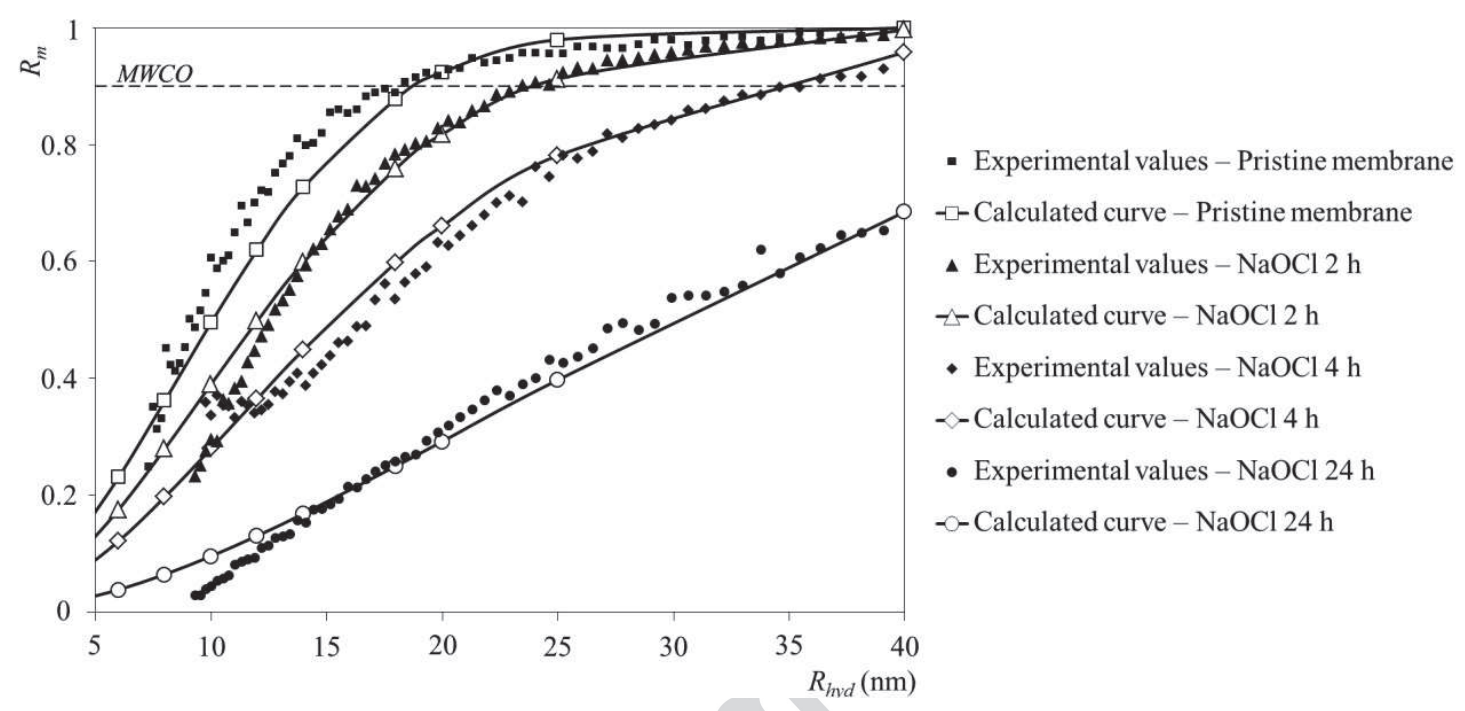

Figure 9: Selectivity curves of pristine and aged membranes ( $\mathrm{NaOCl} 350 \mathrm{ppm}, \mathrm{pH} \mathrm{8})$, comparison between experimental results and calculated ones according to the second scenario. 

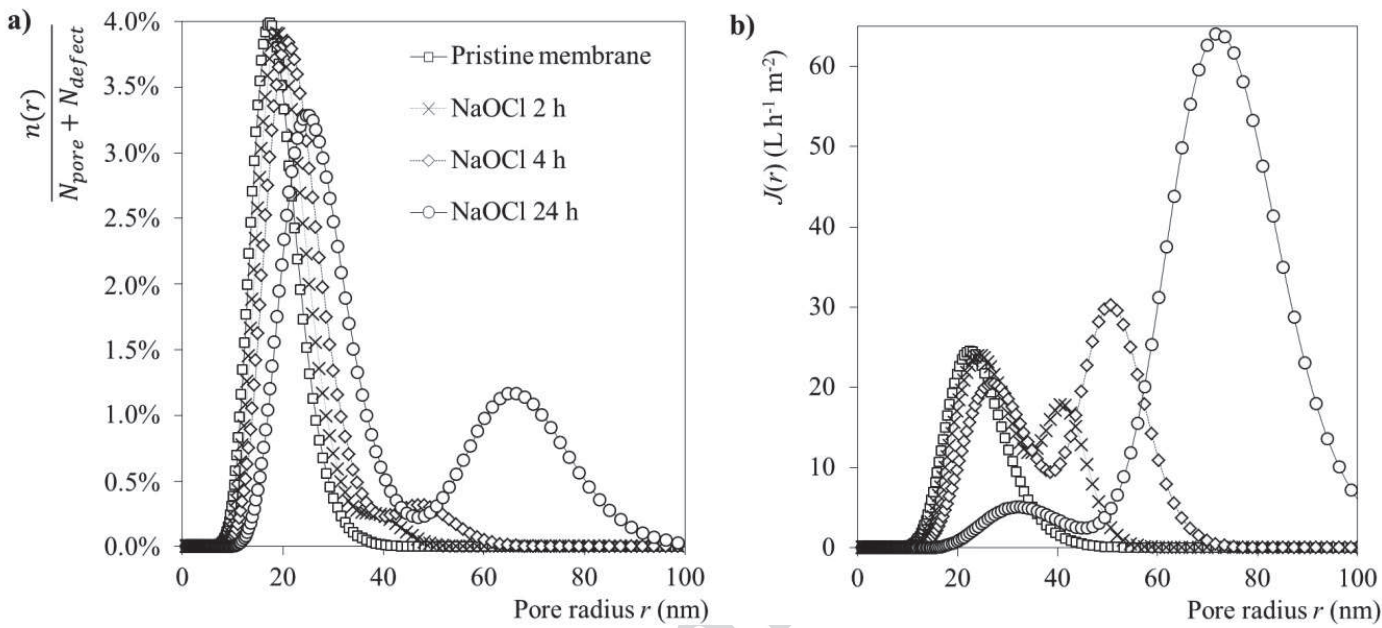

Figure 10: a) $n(r)$ the discontinuous distribution of the number of pores and of defects and b) $J(r)$ the flow density relative to each pore size class for pristine and aged membrane samples according the second scenario 


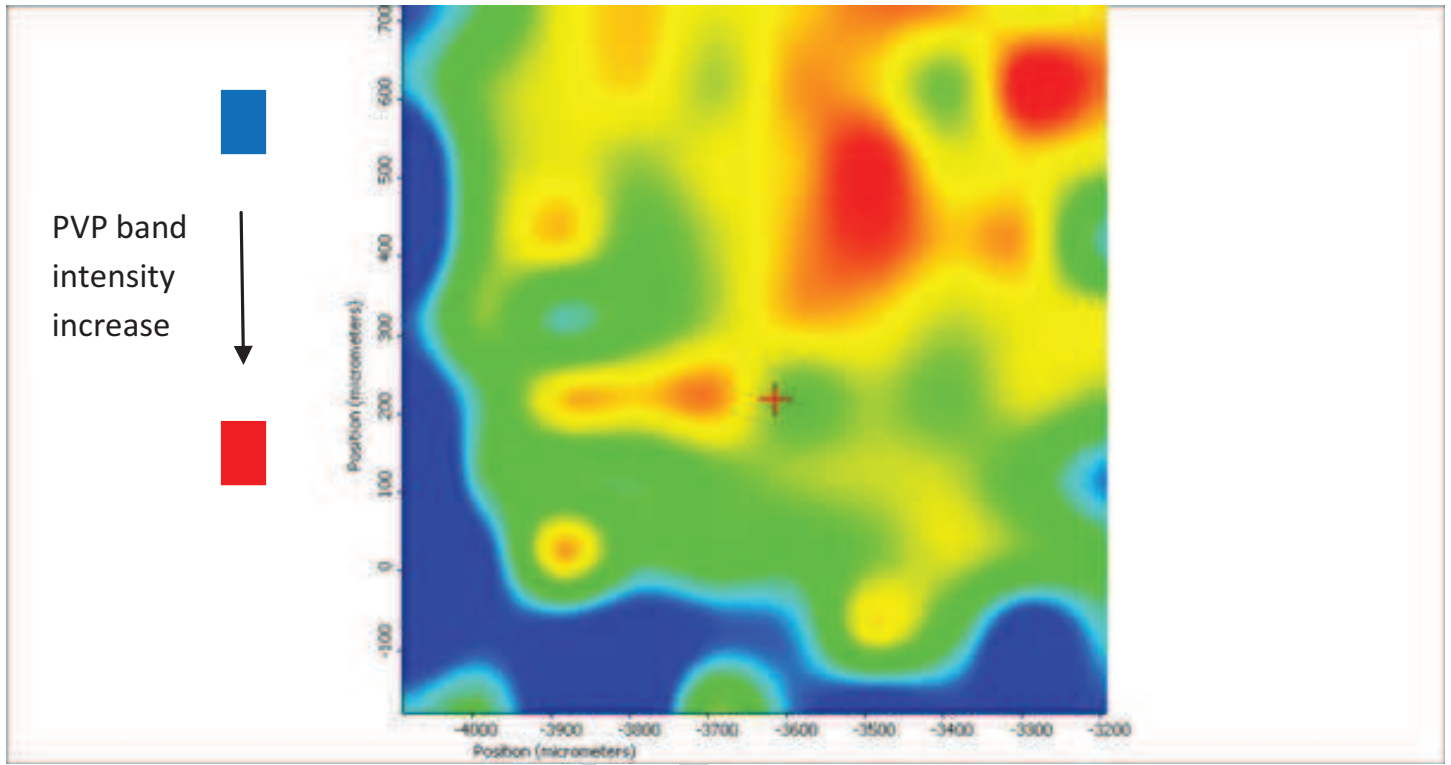

Figure 11: 2D mapping by ATR - IRTF of the inner surface of pristine membrane showing the amide band intensity of PVP (from Prulho [29]) 